\title{
The Effect of Low-Quantity Cr Addition on the Corrosion Behaviour of Dual-Phase High Carbon Steel
}

\author{
Wilson Handoko (iD, Farshid Pahlevani * (i) and Veena Sahajwalla \\ Centre for Sustainable Materials Research and Technology (SMaRT Centre), School of Materials Science \\ and Engineering, The University of New South Wales (UNSW Sydney), Sydney, NSW 2052, Australia; \\ w.handoko@unsw.edu.au (W.H.); veena@unsw.edu.au (V.S.) \\ * Correspondence: f.pahlevani@unsw.edu.au; Tel.: +61-(2)-9385-4433
}

Received: 1 March 2018; Accepted: 19 March 2018; Published: 21 March 2018

\begin{abstract}
Industrial application of high carbon low alloy steel with the dual-phase structure of martensite and austenite has increased drastically in recent years. Due to its excellent compression strength and its high abrasion resistance, this grade of steel has used as a high performance cutting tool and in press machinery applications. By increasing the usage of more corrosive media in industrial practice and increasing the demand for reducing the production cost, it is crucial to understand the effect of the small addition of $\mathrm{Cr}$ on the corrosion behaviour of this grade of steel. In this study, this effect was investigated using Secondary Electron Microscopy (SEM) and in-situ Atomic Force Microscopy (AFM) in the sodium chloride solution. Also, the corrosion rate was measured using the Tafel polarisation curve. It has been found that the small addition of $\mathrm{Cr}$ increased the stability of retained austenite, thus improving its corrosion resistance and reducing its corrosion rate. This effect has been acquired through in-situ high resolution topography images in which the samples were submerged in a corrosive solution. It has been demonstrated that the corrosion rate was reduced when the stability of austenite enhanced.
\end{abstract}

Keywords: high carbon steel; corrosion rate; atomic force microscopy; effect of $\mathrm{Cr}$

\section{Introduction}

The use of high carbon steel has extensively increased in various sectors, and it plays a major role in the production of industrial tools such as high-tensile wires, shear blades, and other applications in mining and pharmaceutical manufacturers [1]. Increasing the usage of more corrosive media in industrial applications to reduce the production cost increased the effect of corrosion in the failure of this grade of steel. The addition of alloying elements such as chromium $(\mathrm{Cr})$ has improved the corrosion resistance of high carbon steel [2]. However, it is crucial to understand the effect of the low-quantity addition of these alloying elements to reduce the production cost associated with it.

In recent study by the authors, the corrosion mechanism of dual-phase high carbon steel has been investigated in detail $[3,4]$. This study has demonstrated that in dual-phase high carbon steel, austenite has a higher potential as the first phase to be corroded, due to carbon partitioning from the martensitic to the austenitic phase and its metastable nature [5]. On the other hand, Rumana et al. investigated the influence of small addition of $\mathrm{Cr}$ on the stability of retained austenite and demonstrated that the small addition of $\mathrm{Cr}$ will increase the stability of retained austenite in dual-phase steels [6,7]. $\mathrm{Cr}$ is one of the essential alloying elements used in steel composition to minimise oxidation and enhance corrosion resistant property [7]. Nonetheless, to acquire the affordable high carbon steel components with their superior properties for many utilisations in industry applications, it is necessary to master the presence of $\mathrm{Cr}$ and its effect on each microstructure on dual-phase high carbon steels. 
This powerful technique, which included potentiodynamic polarisation analysis, was employed in this research to analyse and assess the influence of $\mathrm{Cr}$ on austenite stability on the corrosion rate. Although the electrochemical test was able to provide valuable quantitative and chemical information for the corrosion investigation [8], it was not capable of observing the surface topographical evolution during the corrosion process. Scanning Electron Microscope (SEM) offers high reconstruction images using a targeted beam of electrons on the surface of sample, but it is not able to do in-situ measurement. Atomic Force Microscopy (AFM) $[9,10]$ is not a common technique for studying corrosion behaviour, but the usage of this technique for in-situ investigation of corrosion has been increasingly demonstrated [11-13]. This AFM is adopted for corrosion study in such a way that has changed the conventional technique of observing and analysing the initiation of corrosion in a wide range of metallic materials with different corrosive media in high precision measurement with nano-scale reconstruction [13]. Previous study by the Álvarez-Asencio team proved that using Atomic Force Microscopy (AFM) for corrosion examination on low carbon steel containing $0.2 \% \mathrm{C}$ and $21.2 \% \mathrm{Cr}$ [14] is more efficient and precise in imaging and mapping capabilities over the conventional methods. Other research about corrosion from the Yang team used AFM to investigate the occurrence of passivation in duplex stainless steel containing $0.5 \% \mathrm{C}$ and $22.2 \% \mathrm{Cr}$ [15].

The aim of this research is to investigate the effect of low-quantity $\mathrm{Cr}$ addition on the corrosion behaviour of dual-phase high carbon steel. Using in-situ AFM, it has been shown that the corrosion rate of retained austenite in high carbon steel has been reduced by increasing the $\mathrm{Cr}$ content, which clearly corresponds with increased the stability of retained austenite. These results show that the addition of low-quantity chromium improves corrosion the resistance of high carbon steel and reduces the dependency of alloying elements when using these grades of steel in a more corrosive environment and will open a new range of applications.

\section{Materials and Methods}

\subsection{Material Preparation}

Corrosion behaviour of three different dual phase steel samples with 1.0 C, (0.8-1.0) Mn, (0.1-2.5) $\mathrm{Cr}$ (in wt \%) with different level of chromium concentration and almost similar percentage of retained austenite (\%RA), as shown in Table 1, was studied. Retained austenite percentages in these three types of samples, which have been measured and investigated in pervious study using XRD spectrum [6], are almost in the same range to eliminate the effect of huge variation in retained austenite percentage. Prior to the in-situ AFM investigation, the specimen was precisely cut by Struers Accutom-50 (Struers, Rødovre, Denmark) to suitable dimensions ( $5 \mathrm{~mm} \times 5 \mathrm{~mm} \times 3 \mathrm{~mm}$ ) to fit all the measurements. The samples were mounted and grinded with $\mathrm{SiC}$ abrasive paper up to 2500 grit and polished with fine diamond suspension sequentially to $1 \mu \mathrm{m}$ using Struers Labopol-5 (Struers, Rødovre, Denmark). All specimens were cleaned by ultrasonic cleaner with $\left(\mathrm{CH}_{3}\right)_{2} \mathrm{CO}$ (purity $\geq 99.9 \%$ Sigma-Aldrich) (Unisonics Australia, Brookvale, Australia), rinsed with $\mathrm{C}_{2} \mathrm{H}_{5} \mathrm{OH}$ (purity $\geq 99.5 \%$ Sigma-Aldrich), and then dried. All samples were weighted for weight loss analysis by precision analytical balance, Mettler Toledo XS205 Dual Range. Low concentration of corrosive media, $0.1 \mathrm{M} \mathrm{NaCl}$, was used to investigate the corrosion mechanism and identify different corrosion steps for each phase. To investigate the microstructure of the samples at $t=0$, before corrosion, these samples were etched with $2.0 \%$ Nital solution in order to reveal the microstructure.

Table 1. High carbon martensitic steels with different chemical composition.

\begin{tabular}{ccc}
\hline Sample & Cr (in wt \%) & \% Retained Austenite \\
\hline A & $0.1-0.18 \%$ & $47-50 \%$ \\
B & $0.6-0.80 \%$ & $48-53 \%$ \\
C & $1.8-2.50 \%$ & $57-59 \%$ \\
\hline
\end{tabular}




\subsection{Analytical Methods}

Topographical changes after submerging the samples in corrosive media for different time were investigated with Hitachi S3400X SEM (Hitachi High Technologies America Inc., Schaumburg, IL, USA). A $5 \mathrm{~mm} \times 5 \mathrm{~mm}$ surface area of steel sample was lightly marked by four-square-point from Vickers hardness indenter to track the corrosion process. The AFM study was performed with Bruker BioScope Catalyst ${ }^{\mathrm{TM}}$ (Bruker, Santa Barbara, CA, USA), which is equipped with ScanAsyst-Fluid+ (Bruker, Santa Barbara, CA, USA), fitted with silicon-tip on-nitride-lever $(k=0.7 \mathrm{~N} / \mathrm{m})$ for both air and liquid measurement conditions. Initial scan on the air condition was conducted as a reference before the sample was immersed into corrosive solution, $0.1 \mathrm{M} \mathrm{NaCl}$. The sample container was filled by the $\mathrm{NaCl}$ solution for continuous scan up to $105 \mathrm{~min}$. As each scan took $15 \mathrm{~min}$, the results are with $15 \mathrm{~min}$ interval. This experiment was conducted in the scan rate of $0.355 \mathrm{~Hz}$, scan size $5 \mu \mathrm{m} \times 5 \mu \mathrm{m}$, and with automatic peak force set point to achieve the optimum image resolution. Evolution of surface morphology was observed in the scanned area through continuous scanning within the original area before immersion. The evaporation was not a major issue, as the surface analysis process was short period of time at room temperature $24 \pm 1{ }^{\circ} \mathrm{C}$. All AFM images were processed and analysed with NanoScope Analysis version 1.7. Electrochemical test was carried out by using Versatile Multipotentiostat VSP-300 (EC-Lab®, Claix, France) equipped by the EC-Lab software v11.01. A corrosion flat cell kit with three electrodes (reference, counter, and working) were connected to this instrument. The potentiondynamic polarisation curves were generated from $-0.25 \mathrm{~V}$ to $0.25 \mathrm{~V}$ with scan rate at $5 \times 10^{-4} \mathrm{~V} / \mathrm{s}$. Calculation of mils penetration per year can be determined from the obtained corrosion rate, $i_{\text {corr }}$ values.

\section{Results and Discussion}

SEM microstructure images of three different samples as received and after submerging in $0.1 \mathrm{M}$ $\mathrm{NaCl}$ solution for different time were summarised in the Figure 1. From the microstructure of samples at different time it is important to observe that the austenite phase is attached by the solution at the beginning. Although all of the topographical images were mirror-polished and lightly etched, the surface topographies were coarsened by phase differentiating in the corrosive media. The magnification of $\sim 5000 \times$ at low energy Secondary Electron (SE) mode was performed on each sample. It can be seen that when $t=0 \mathrm{~h}$, the different shape, size, orientation, and volume fraction of each phase was clearly visible in the microstructural analysis. Sample A possessed the groups of austenitic phases with length and largely in size of martensitic phase, as it had the lowest $\mathrm{Cr}$ content and retained austenite. On the other hand, sample B was larger in terms of shape, size, and distribution of retained austenite $(48-53 \%)$, with narrower and shorter martensite phases. Moreover, sample C had blocky and sturdy austenitic phase with less spread of finer martensitic phase, as it dominated the $\mathrm{Cr}$ content value.

Different phenomena occurred as per effect of microstructures that varied in terms of shape, size, and distribution of each phase. Sample A shows the preferential attack on austenitic phase in Figure $1 \mathrm{~b}$. This phenomena occurred until $t=2 \mathrm{~h}$ in Figure $1 \mathrm{c}$, with little degradation on martensitic phase at this stage. Compared to sample B, it exhibited similar behaviour due to slight increase in $\mathrm{Cr}$ content. However, sample $\mathrm{C}$ was capable of resisting more the corrosion attack, as the retained austenite remained almost unchanged with moderate damage to the martensitic phase at $t=2 \mathrm{~h}$, as presented in Figure 1i. It can be said that the addition of low-quantity $\mathrm{Cr}$ chemical element can lead to enhancement of retained austenite phase stability, as well as reduction of grain boundary corrosion that occurred in, along, and within both phases interface. A summary of the microstructure evolution as function of corrosion process time is presented in Table 2 below. Further investigations were conducted to prove the decreased corrosion rate, as $\mathrm{Cr}$ increases are described in the weight loss and electrochemical measurements.

The comparison of corrosion behaviour from these samples has been proved through the variety stabilities and the boundary structures of retained austenite, in which blocky austenitic grain size possesses a lower grain boundary density [16]. Previous research on the effect of dual-phase grain 
size on corrosion behaviour proved that it not only decreased the oxidation of iron that can lead to the corrosion reaction mechanism but also decreased the overall corrosion rate [16]. Further evidence from previous study on the effect of $\mathrm{Cr}$ addition on retained austenite stability demonstrated that increasing critical $\mathrm{Cr}$ percentage was adequate to offer a significant advantageous of stabilisation on the austenitic phase without changing presence of alloying elements [6]. As a consequence, corrosion-resistant properties of high carbon steel were improved as $\mathrm{Cr}$ content escalated, with restored shape, size, and distribution of austenitic phase that was able to improve austenite phase stability and, hence, reduction in grain boundary corrosion and corrosion rate.
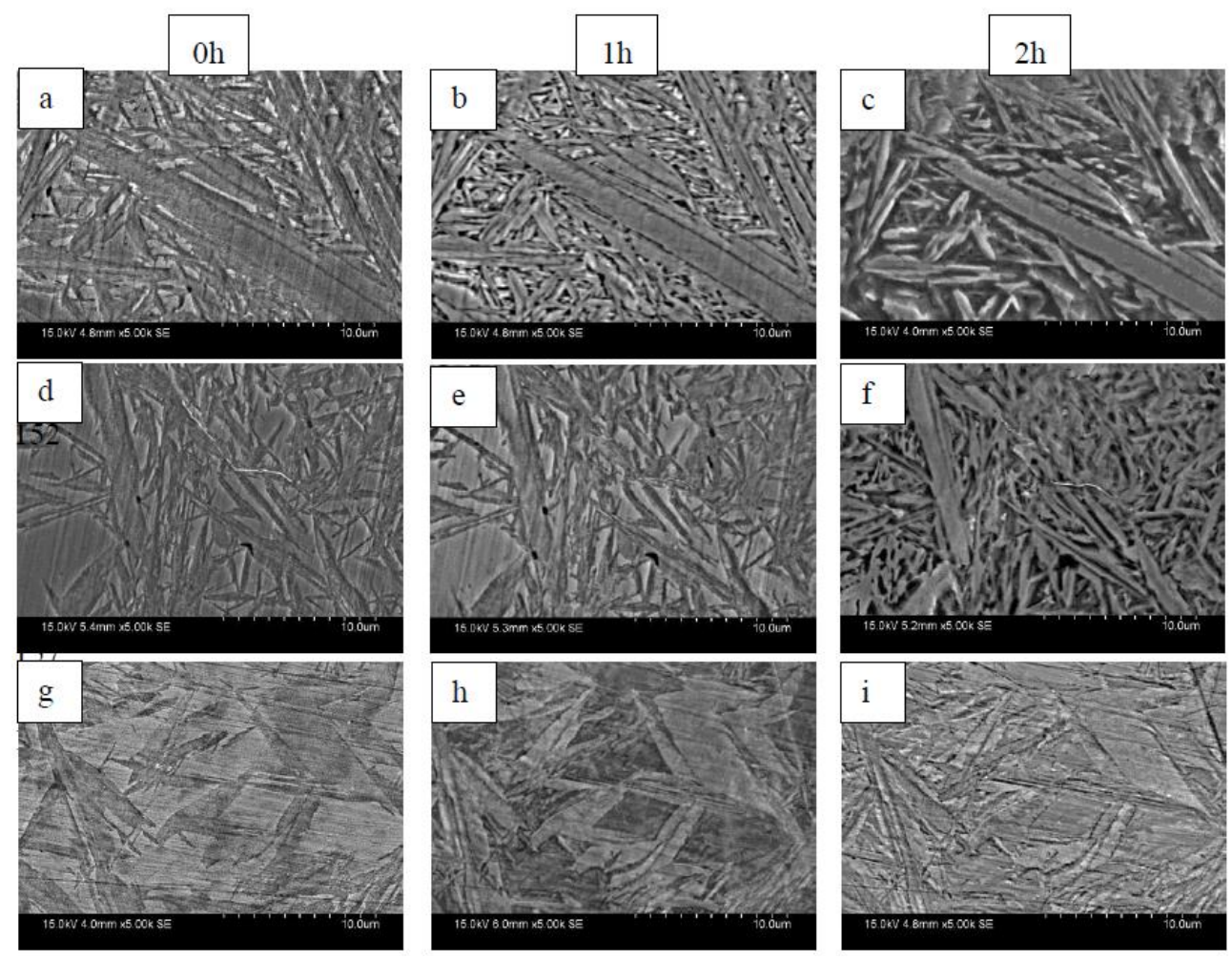

Figure 1. SEM images of different percentage of $\mathrm{Cr}$, in which $(\mathbf{a}-\mathbf{c})$ with $0.10-0.18 \% \mathrm{Cr}$; (d-f) with $0.60-0.80 \% \mathrm{Cr}$; and (g-i) with $1.80-2.50 \% \mathrm{Cr}$. All samples were etched at $t=0 \mathrm{~h}$.

In-situ investigation was carried out up to nano-scale resolution to strengthen the evidence by using Atomic Force Microscope (AFM). The generated three-dimensional mappings from the high carbon steel specimens were continuously recorded to observe surface evolution over a period of time. The entire Figure 2(i) correlates to the first scan ( $t=0 \mathrm{~min})$ immediately before it was brought into contact with $\mathrm{NaCl}$ solution. Exposed polishing scratches and two-phase microstructure peaks-and-valleys-like are visible, which means surface was affected by the corrosive solution. All Figure 2(ii) demonstrate the epitaxial growth of oxide products that occupied the roughened surface area; scratches were barely visible at this stage. Furthermore, at $t=60 \mathrm{~min}$ (5th scan), it can be observed from sample A that the scanned area was laid on martensitic phase, while sample B and C showed flatted-like surface (as martensite), with clear separation (as grain boundary) and valley (as austenite). Additionally, the flatted-like region was believed to be martensitic phase, since the high number on $y$-axis scale led to the overlapping of small-scaled martensite microstructure. In order to prove this phenomenon, the enlargement area of 3-D images has been presented in Figure 2(iii) on sample B and C, as the existing corroded martensite crystalline structure.

The AFM is capable of recording the real time information of the surface evolution by corrosion process in nano-scale reconstruction. It is essential to provide line scan profile analysis to prevent distortion by observation from certain angles and colours from three-dimensional images. Evolution of 
all of the surface modifications with series of peaks and valleys by the influence of $0.1 \mathrm{M} \mathrm{NaCl}$ solution is represented as line scan profile, as shown in Figure 3. The preferential attack on austenite at the early stage was due to the different potential energy in the grain boundary between martensite-austenite interfaces. The phenomenon can be seen, as martensite remained at a higher elevated surface than retained austenite at $t=60 \mathrm{~min}$ throughout the end of experiment at $t=105 \mathrm{~min}$. In addition, this preferential attack on austenite microstructure was related to the different $\mathrm{Cr}$ content that affected the shape, size, and distribution of each grain boundary interface. Another aspect that needs to be considered is the feasible existence of chromium-depleted zone along the martensite-austenite grain boundaries, as it has much lower corrosion resistance than other areas [17]. Additionally, local $\mathrm{Cr}$ depletions are normally caused by solid-state precipitation of enriched Cr precipitate that can lead to loss of corrosion-resistant property [17].

At seventh scan or $t=105 \mathrm{~min}$, all sample surface morphology remained insignificant alteration, because the corrosion rate gradually decreased, as $\mathrm{Cr}$ acted to increase resistance to oxidation, improve stability of retained austenite, and reduce the dissolution of iron atoms that caused the corrosion mechanisms to occur. Martensite possesses higher hardness properties than austenite, but austenite is responsible for the corrosion resistance in this dual-phase high carbon steel. Addition of low-quantity $\mathrm{Cr}$ increased the stabilisation of retained austenite, improving corrosion resistance overall, as well as increasing high hardness in martensitic structure [18].

Although carbon is unlikely to be considered from a corrosion perspective, a study proved that supersaturated carbon in austenitic structure is able to offer a very high hardness, as well as be beneficial to corrosion-resistant properties in dual-phase high carbon steel $[17,19]$. The effect of low-quantity addition of $\mathrm{Cr}$ content deteriorates the intensity of the grain boundary corrosion, thus improving retained austenite stability that slows down the corrosion rate accordingly. Other influences of increased $\mathrm{Cr}$ on retained austenite offer larger and sturdier grain boundary and exceptional enhancement of its stability, thus leading to the improvement of corrosion resistance properties, as the corrosion rate is reduced [20]. The stability of austenitic structure was improved, as its grain boundary density decreased and grain boundary structure became substantial along the interfaces of martensite-austenite [21]. By sequence, the sample $C$ has lowest lattice mismatch grain boundary energy, because additional of low-quantity of $\mathrm{Cr}$ caused enhancement in stability of austenite; hence, it has less propensity on electrochemical reaction and corrosion propagation than sample A and B.

From these microstructural characterisations, the grain boundary corrosion and distribution of growth pits were reduced as the outcome of increased $\mathrm{Cr}$ percentage and preferential damage on one of the dual phases of high carbon steel, austenite, was followed by martensite phase. The immersion of dual-phase high carbon steel specimen into a $0.1 \mathrm{M} \mathrm{NaCl}$ media during the AFM performed in the early stage of corrosion initiation and continuous scanned area provided live information of surface changes on the targeted area. Speculating that the martensitic was unaltered by the evolution of the surface of steel at the early stage, any modifications of surface roughness could be related to the dissolution and preferential attack of austenitic microstructure, and the total steel lost could be simply determined.

Table 2. Microstructural evolution after the corrosion process for 2-h immersion in $0.1 \mathrm{M} \mathrm{NaCl}$.

\begin{tabular}{ccccc}
\hline Sample & Cr (in wt \%) & \% Retained Austenite & 1-h Corrosion & 2-h Corrosion \\
\hline A & $0.10-0.18 \%$ & $47-50 \%$ & $\begin{array}{c}\text { Austenite: moderate damaged; } \\
\text { Martensite: undamaged }\end{array}$ & $\begin{array}{c}\text { Austenite: moderate damaged; } \\
\text { Martensite: slight damaged }\end{array}$ \\
\hline B & $0.60-0.80 \%$ & $48-53 \%$ & $\begin{array}{c}\text { Austenite: moderate damaged; } \\
\text { Martensite: undamaged }\end{array}$ & $\begin{array}{c}\text { Austenite: moderate damaged; } \\
\text { Martensite: slight damaged }\end{array}$ \\
\hline C & $1.80-2.50 \%$ & $57-59 \%$ & $\begin{array}{c}\text { Austenite: unmodified; } \\
\text { Martensite: slight damaged }\end{array}$ & $\begin{array}{c}\text { Austenite: almost unmodified; } \\
\text { Martensite: } \text { moderate damaged }\end{array}$ \\
\hline
\end{tabular}


(i)

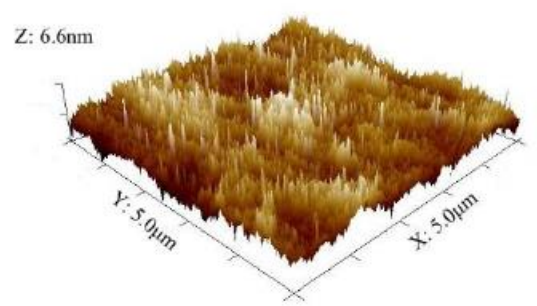

(i)

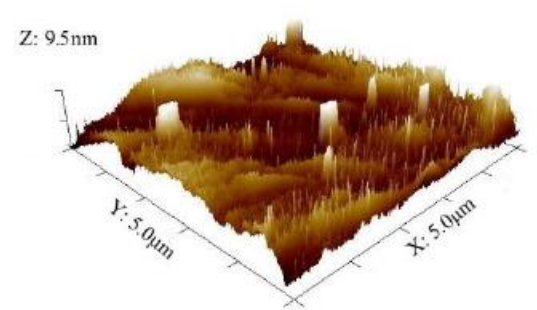

(i)

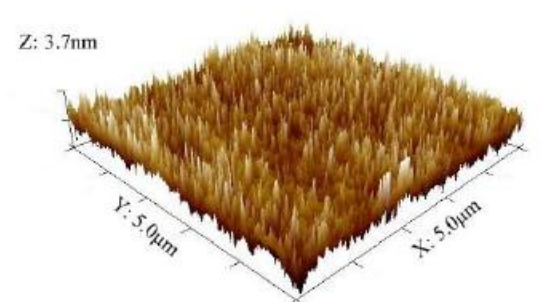

(ii)

Sample A

Z: $4.6 \mathrm{~nm}$

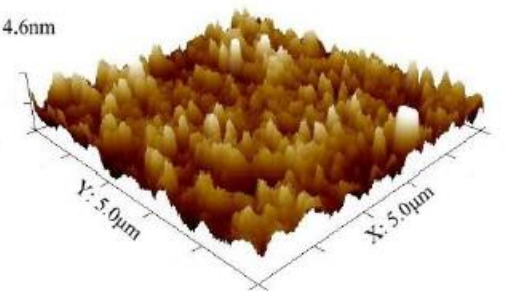

(ii)

Sample B

$\mathrm{Z:} 40.6 \mathrm{~nm}$

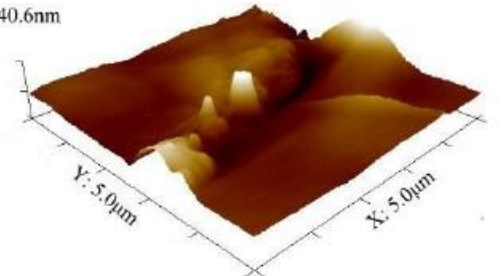

(ii) Sample C

Z: $26.5 \mathrm{~nm}$

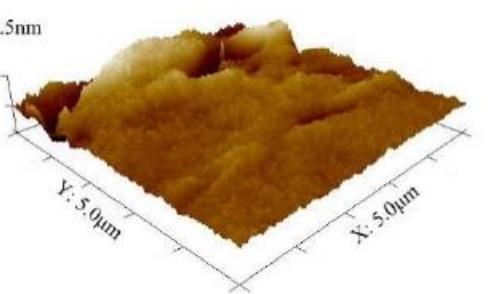

(iii)

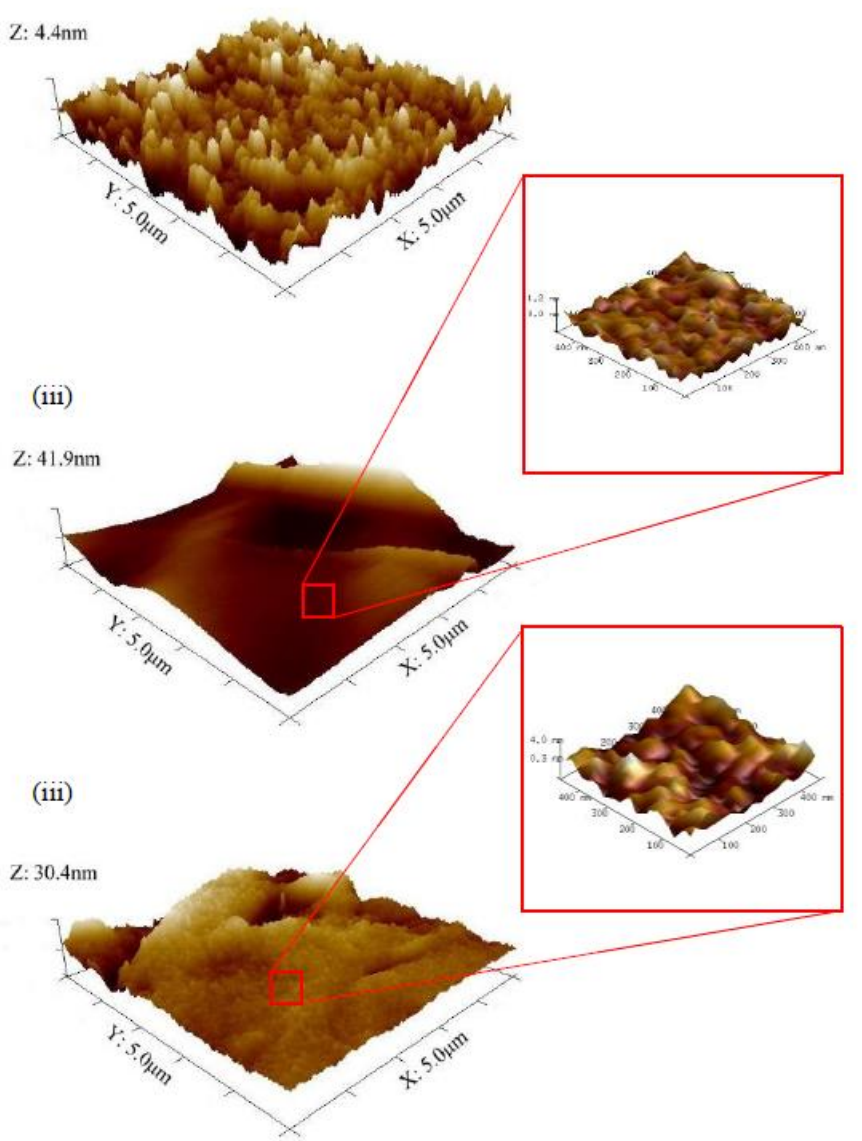

Figure 2. In-situ AFM three-dimensional topography images of high carbon martensitic steel surface at (i) 0 min; (ii) 60 min; and (iii) 105 min, the exposure to $0.1 \mathrm{M}$ $\mathrm{NaCl}$ solution. 

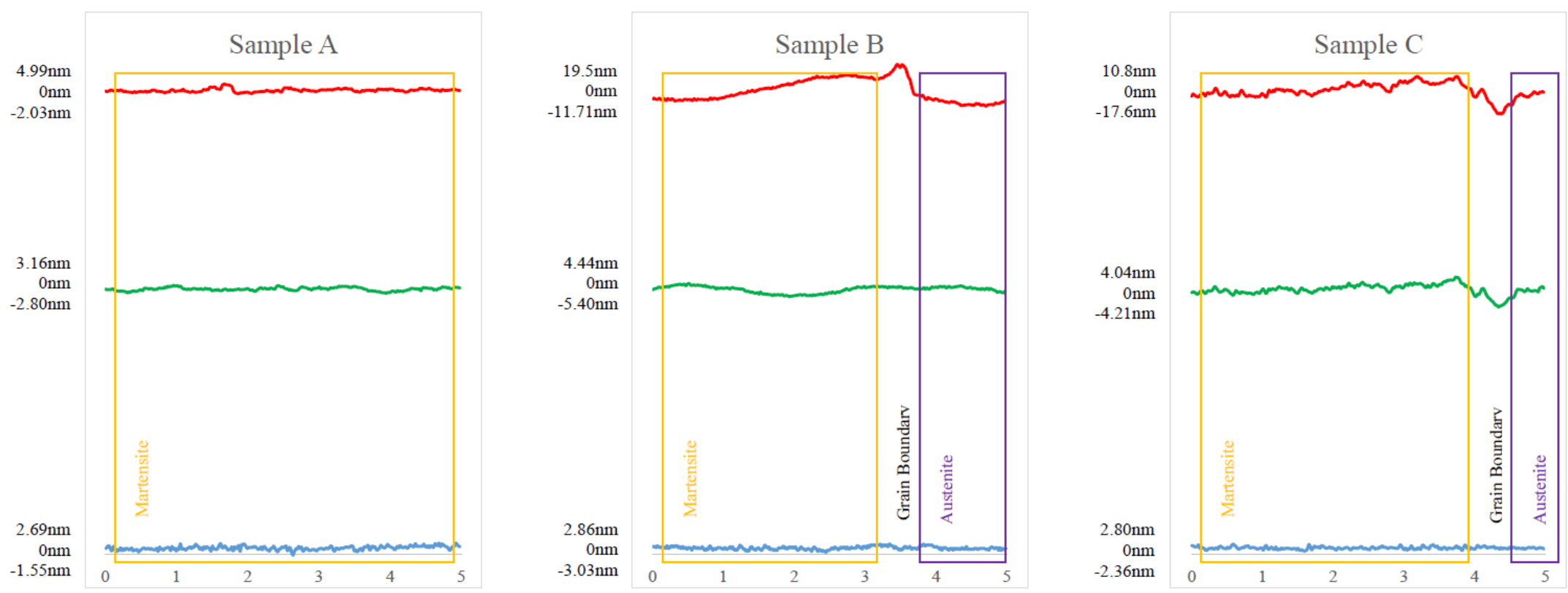

Figure 3. Displays of line scan profiles acquired from AFM results, with separation distance between each line to prevent overlapping-0 min (blue), 60 min (green), and $105 \mathrm{~min}$ (red); labelled of microstructure region: martensite (yellow), grain boundary (black), and austenite (purple). 
The acquired graph was from the weight loss analysis with highly precise analytical balance, and it was possible to determine the corrosion rate as function of time, presented in Figure 4 . These valuable data were compiled and fitted with second-order polynomial expression to obtain the corrosion rate function from its first differentiation. Rapid weight loss was observed from the first two hours of the corrosion process; after this time, the corrosion rate decreased. This was due to the fact that austenitic phase started to corrode and followed by insignificant change of martensitic phase, as there was more $\mathrm{Cr}$ content in steel that increased the retained austenite stability; thus, the weight loss lessened.

Each corrosion rate result was extracted from the projected graph using the derivation of the polynomial, as follows:

For sample A:

$$
\begin{aligned}
& y=-0.0231 x^{2}+0.8232 x+1.0649 \\
& y^{\prime}=-0.0462 x+0.8232
\end{aligned}
$$

For sample B:

$$
\begin{aligned}
& y=-0.0133 x^{2}+0.5054 x+0.4302 \\
& y^{\prime}=-0.0266 x+0.5054
\end{aligned}
$$

For sample C:

$$
\begin{aligned}
& y=-0.0016 x^{2}+0.0585 x+0.0422 \\
& y^{\prime}=-0.0032 x+0.0585
\end{aligned}
$$

These results alleged that the evidence for corrosion rate is extremely high in sample A, followed by medium rate in sample B and lower rate in sample $C$, which is influenced by lowest Cr percentage. It suggested that the intensity of the corrosion increased, especially on and along grain boundaries interface, as the volume fraction of retained austenite decreased and refined austenite microstructure. The corrosion rate can be acquired from the plotted graph of average weight loss with respect to time and $\% / h$ unit; $x$ refers to the evolution on the surface of sample over the time in hours. The corrosion rate can be determined using other methods, based on the Faraday's law, regardless of the correlation of materials loss with the function of time [22] and electrochemical experiments such as potentiodynamic polarisation curves, which is a very effective analysis tool for corrosion test. The mechanism of pitting initiation emergence process as the cause of the preferential attack on one of dual-phase structure is widely acknowledged as Jose Rodolvo Galvele's pitting theory about the multi-directional attack [23]. Furthermore, the concept states that as the pit depth expands, the corrosion attack rate decreases; hence, this is satisfied with results in this in-situ study, employing the AFM in live recording mode of surface evolution on dual-phase high carbon steels by $\mathrm{NaCl}$ solution for hours.

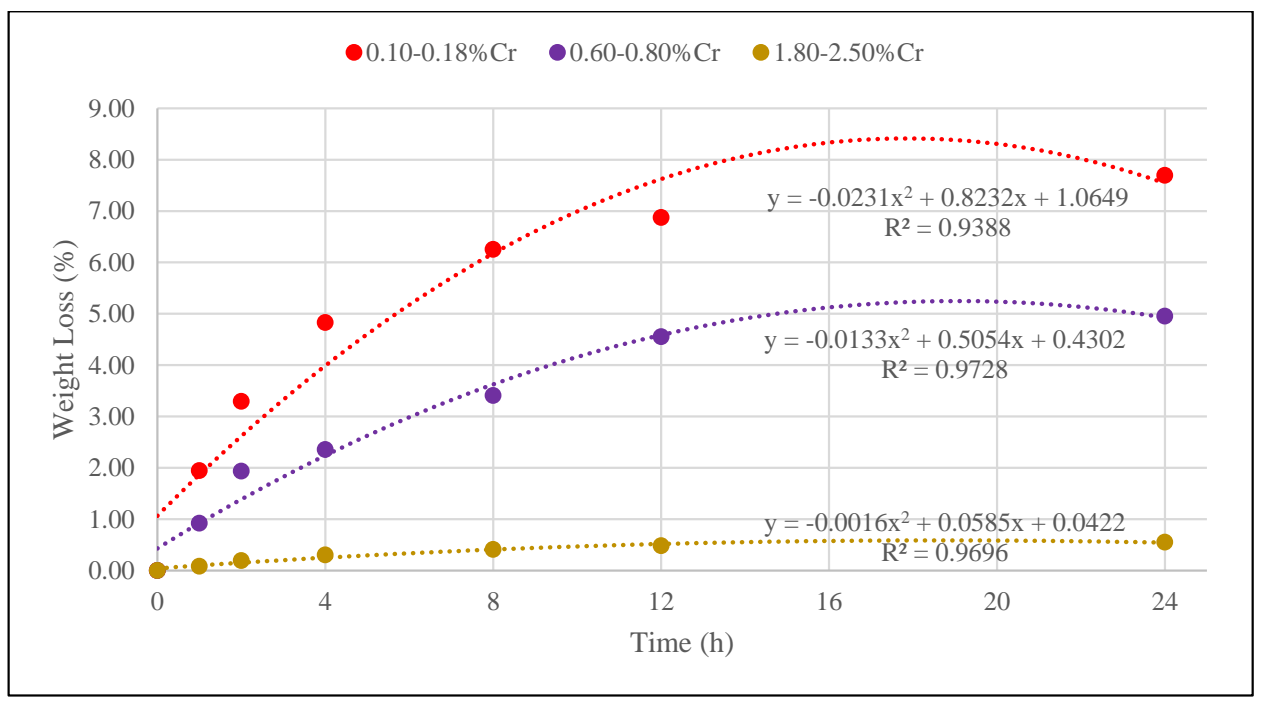

Figure 4. The determination of corrosion rate through the average surface roughness over a period of time. 
Further evidence was provided and an investigation was performed to support corrosion rate results that were acquired from the weight loss analysis by plotting Tafel polarisation curve [24,25] from the multichannel potentiostat instrument, as shows in Figure 5 below:

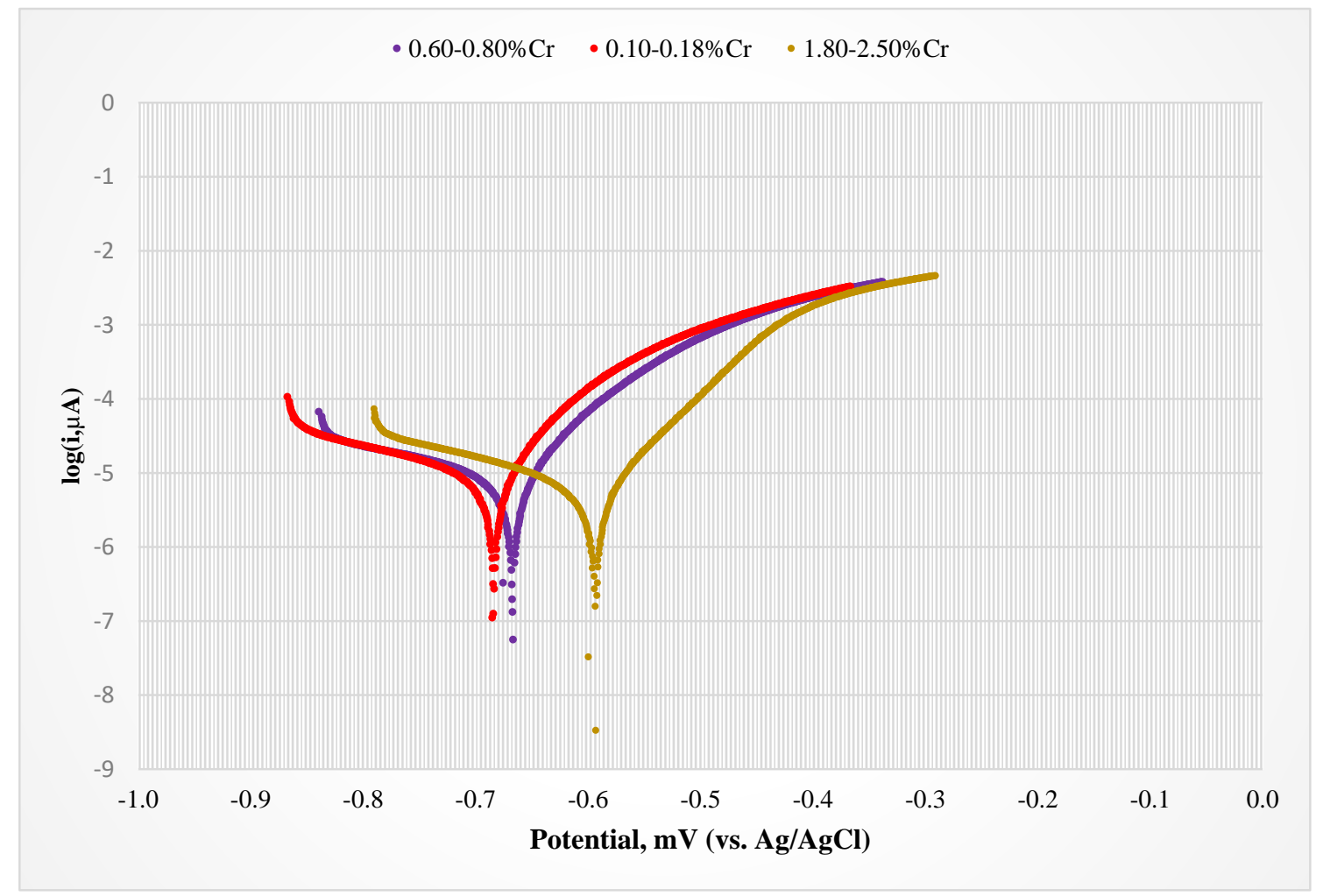

Figure 5. The cathodic and anodic (Tafel) polarisation curves for dual-phase high carbon steels with different $\mathrm{Cr}$ content in $0.1 \mathrm{M} \mathrm{NaCl}$ solution.

The extrapolation of Tafel curves presented the combination of cathodic slope (left hand side) and anodic slope (right hand side). The cathodic curves were defined by activation control and performed linearly in correspondence with Tafel plot relationship, while the deviation from anodic curves contributed to the passivation, corrosion, and degradation on anode surface of the sample [26-31]. Extrapolated lines from each cathodic and anodic Tafel region were lined up parallel to the best fit of each linear slope. Intersected point between cathodic and anodic current was joined to determine the current density of corrosion rate $\left(\mathrm{i}_{\text {corr }}\right)$ and potential values.

From these potentiodynamic polarisation curves, a conclusion can be withdrawn that increased low-quantity of $\mathrm{Cr}$ in dual-phase steels improved its retained austenite stability, as both cathodic and anodic curves intersected, decreasing the magnitudes in terms of each current density and potential, meaning that corrosion rate reduced. Additionally, to determine the precise calculation of the Mils Penetration per Year (MPY) of each sample that corresponded to current density of corrosion rate $\left(i_{\text {corr }}\right)$ from the graph, the calculation of high carbon steel Equivalent Weight $(E W)$ is required based-on weight percentage of each different elemental composition, which can be determined by the formula $[26,27]$ below:

$$
\begin{aligned}
\text { Equivalent of } \mathrm{Fe} & =\frac{\mathrm{wt} \% \times \text { Valence value }}{\text { Atomic weight }} \\
\mathrm{EW} \text { of } \mathrm{Fe} & =\frac{100}{\text { Equivalent of } \mathrm{Fe}}
\end{aligned}
$$


Then, the Mils Penetration per Year can be calculated by the given formula [30,31]:

$$
\text { Mils Penetration per Year }(\text { MPY })=\frac{0.13 \times \mathrm{i}_{\text {corr }} \times \mathrm{EW}}{\text { Density }}
$$

All results are tabled as presented in Table 3. The MPY results decreased from 4.857 to 2.954 as the corrosion resistance properties of high carbon steel increased. As $\mathrm{Cr}$ content escalated, volume fraction of retained austenite increased and its stability improved, which minimised the grain boundary corrosion, as less iron atoms moved that accelerated corrosion reaction, thus improving the corrosion resistant properties.

Table 3. Comparison of the effect of different chromium percentages on the corrosion rate and mils penetration per year of dual-phase high carbon steels.

\begin{tabular}{ccccccc}
\hline Sample & $\begin{array}{c}\text { Density } \\
\left(\mathbf{g} / \mathbf{c m}^{\mathbf{3}}\right)\end{array}$ & $\begin{array}{c}\text { Tested Area } \\
\left(\mathbf{c m}^{\mathbf{2}}\right)\end{array}$ & $\begin{array}{c}\text { Equivalent } \\
\text { Weight }(\mathbf{g})\end{array}$ & $\begin{array}{c}\text { Potential } \\
(\mathbf{m V})\end{array}$ & $\begin{array}{c}\mathbf{i}_{\text {corr }} \\
(\boldsymbol{\mu A})\end{array}$ & $\begin{array}{c}\text { Mils Penetration } \\
\text { per Year }(\mathbf{m p y})\end{array}$ \\
\hline $\mathrm{A}$ & 7.6058 & 1 & 28.65 & -695.3 & 9.919 & 4.857 \\
$\mathrm{~B}$ & 7.6067 & 1 & 28.79 & -676.7 & 9.839 & 4.841 \\
$\mathrm{C}$ & 7.6531 & 1 & 29.20 & -590.7 & 5.955 & 2.954 \\
\hline
\end{tabular}

\section{Conclusions}

The dual-phase microstructural study has revealed that the corrosion-resistant properties in high carbon steel are improved by the addition of low-quantity $\mathrm{Cr}$ content that is correlated to the increasing stability of retained austenite. By performing standard corrosion tests using microstructural and electrochemical analysis on dual-phase high carbon steel samples, we delivered a new perspective on the improvement of its corrosion-resistant properties. The findings have developed prerequisites for new materials and advanced applications regardless of the corrosion-resistant properties that are based on the dual-phase high carbon steel with a cost-effective production line. The effect of the $\mathrm{Cr}$ element on the stability of retained austenite, because of the blocky, large austenitic grain size that reduced its grain boundary density, the lower dissolution of iron atoms that initiated the corrosion reaction mechanism, and the lower corrosion rate thus improved the corrosion resistance of the high carbon steels without changing their alloying elements.

Constant scanning with AFM on the surface of sample in which it was submerged into $0.1 \mathrm{M} \mathrm{NaCl}$ solution proved it was feasible to follow the very beginning stage of the corrosion initiation process, since the mechanical effect is more imperative to austenite, while the chemical effect is more essential to the martensite microstructure. The acquired equation of corrosion rate over a period of time into the immersion of $\mathrm{NaCl}$ media is in positive agreement with the decreased corrosion rate, owing to the increased stability of retained austenite, due to increased $\mathrm{Cr}$ content and further investigations that strengthen the evidence of extrapolation on the Tafel polarisation curves. To cope with the continuously increased use of more corrosive media in industrial practice and the higher demand for minimising production costs, it is imperative to understand the effect of the low-quantity addition of $\mathrm{Cr}$ on the corrosion behaviour of this grade of steel. Therefore, it can be predicted that high-carbon steels with a high level of $\mathrm{Cr}$ and retained austenite have many advantages in manufacturing applications, as they deliver improvements in corrosion resistance, hardness, and robustness for many applications. As a result, reducing the cost of a high percentage of alloying elements correlated with the failure of high-carbon steel components.

Acknowledgments: This research was supported under Australian Research Council's Industrial Transformation Research Hub funding scheme (project IH130200025). The authors acknowledge the facilities and the scientific and technical assistance of the Australian Microscopy \& Microanalysis Research Facility at the Electron Microscope Unit, UNSW Sydney.

Author Contributions: Wilson Handoko performed experiments and data analysis. Farshid Pahlevani designed the project and experiments and critically analysed the data. Veena Sahajwalla supervised the study and gave 
suggestions on revising the manuscript. Wilson Handoko wrote the manuscript and all authors' analysed data, discussed the results, and read and approved the final manuscript.

Conflicts of Interest: The authors declare no conflicts of interest.

\section{References}

1. Azazi, A.; Shafaei, S.Z.; Naoparast, M.; Karamoozian, M. An investigation of the corrosive wear of steel balls in grinding of sulphide ores. Int. J. Min. Geo-Eng. 2015, 49, 83-91.

2. Park, S.; Lee, S.; Kim, J. Effect of chromium on the corrosion behavior of low alloy steel in sulfuric acid. Met. Mater. Int. 2012, 18, 975-987. [CrossRef]

3. Handoko, W.; Pahlevani, F.; Sahajwalla, V. Corrosion Behaviour of Dual-Phase High Carbon Steel-Microstructure Influence. J. Manuf. Mater. Process. 2017, 1, 21. [CrossRef]

4. Handoko, W.; Pahlevani, F.; Sahajwalla, V. Effect of Retained Austenite Stability in Corrosion Mechanism of Dual Phase High Carbon Steel. World Academy of Science, Engineering and Technology. Int. J. Mater. Metall. Eng. 2018, 12. [CrossRef]

5. Gouné, M.; Danoix, F.; Allain, S.; Bouaziz, O. Unambiguous carbon partitioning from martensite to austenite in Fe-C-Ni alloys during quenching and partitioning. Scr. Mater. 2013, 68, 1004-1007. [CrossRef]

6. Hossain, R.; Pahlevani, F.; Sahajwalla, V. Effect of small addition of Cr on stability of retained austenite in high carbon steel. Mater. Charact. 2017, 125, 114-122. [CrossRef]

7. Hossain, R.; Pahlevani, F.; Quadir, M.; Sahajwalla, V. Stability of retained austenite in high carbon steel under compressive stress: An investigation from macro to nano scale. Sci. Rep. 2016, 6, 34958. [CrossRef] [PubMed]

8. Annergren, I. Electrochemical Impedance Spectroscopy for In Situ Studies of Anodic Dissolution and Pitting Corrosion of Iron-Chromium alloys. Ph.D. Thesis, Royal Institute of Technology, Stockholm, Sweden, 1996.

9. Pittenger, N.E.B.; Chanmin. Quantitative Mechanical Mapping at nanoscale with Peak Force QNM; Bruker Application Note; Bruker: Santa Barbara, CA, USA, 2009; pp. 1-12.

10. Döner, A.; Solmaz, R.; Özcan, M.; Kardaş, G. Experimental and theoretical studies of thiazoles as corrosion inhibitors for mild steel in sulphuric acid solution. Corros. Sci. 2011, 53, 2902-2913. [CrossRef]

11. Anantha, K.; Örnek, C.; Ejnermark, S.; Medvedeva, A.; Sjöström, J.; Pan, J. In Situ AFM Study of Localized Corrosion Processes of Tempered AISI 420 Martensitic Stainless Steel: Effect of Secondary Hardening. J. Electrochem. Soc. 2017, 164, C810-C818. [CrossRef]

12. Wang, B.; Du, M.; Zhang, J.; Gao, C. Electrochemical and surface analysis studies on corrosion inhibition of Q235 steel by imidazoline derivative against $\mathrm{CO}_{2}$ corrosion. Corros. Sci. 2011, 53, 353-361. [CrossRef]

13. Fréchard, S.; Martin, F.; Clément, C.; Cousty, J. AFM and EBSD combined studies of plastic deformation in a duplex stainless steel. Mater. Sci. Eng. A 2006, 418, 312-319. [CrossRef]

14. Hengerer, F.; Nierlich, W.; Volkmuth, J.; Nutzel, H. Dimensional stability of high carbon bearing steels. Ball Bear. J. 1988, 231, 26-31.

15. Yang, X.; Castle, J. Using in situ AFM to investigate corrosion and passivation of duplex stainless steels. Surf. Interface Anal. 2002, 33, 894-899. [CrossRef]

16. Remmerswaal, T. The Influence of Microstructure on the Corrosion Behaviour of Ferritic-Martensitic Steel: 3.2 Influence of Prior Austenite Grain Size on Corrosion Properties. Master's Thesis, Delft University of Technology, Delft, The Netherlands, 2015; pp. 57-62.

17. ASTM International. Chapter 6: Austenitic Stainless Steel. In Stainless Steels for Design Engineers; ASTM International: Philadelphia, PA, USA, 2008; pp. 69-78.

18. Li, X.Y.; Zhao, L.M.; Qun, F.L.; Wang, H.Y.; Ching, F.; Hua, M. Effects of Mn on Corrosion Resistant Property of AZ91 Alloys. Rare Met. Mater. Eng. 2014, 43, 278-282.

19. Vasil'eva, A.; Prokoshkin, D.; Goryushin, V. Effect of chromium on strain hardening of martensite. Met. Sci. Heat Treat. 1974, 16, 507-510. [CrossRef]

20. Jirková, H.; Kučerová, L.; Mašek, B. The Effect of Chromium on Microstructure Development during Q-P Process. Mater. Today Proc. 2015, 2, S627-S630. [CrossRef]

21. Abreu, H.; Carvalho, S.; Neto, P.L.; Santos, R.; Freire, V.; Silva, P.; Tavares, S. Deformation induced martensite in an AISI 301LN stainless steel: Characterization and influence on pitting corrosion resistance. Mater. Res. 2007, 10, 359-366. [CrossRef] 
22. Andrade, C.; Alonso, C. Corrosion rate monitoring in the laboratory and on-site. Constr. Build. Mater. 1996, 10, 315-328. [CrossRef]

23. Gravano, S.; Galvele, J.R. Transport processes in passivity breakdown-III. Full hydrolysis plus ion migration plus buffers. Corros. Sci. 1984, 24, 517-534. [CrossRef]

24. Abd El-Lateef, H.M.; Khalaf, M.M. Corrosion resistance of $\mathrm{ZrO}_{2}-\mathrm{TiO}_{2}$ nanocomposite multilayer thin films coated on carbon steel in hydrochloric acid solution. Mater. Charact. 2015, 108, 29-41. [CrossRef]

25. Ha, H.; Seo, W.; Park, J.; Lee, T.; Kim, S. Influences of Mo on stress corrosion cracking susceptibility of newly developed FeCrMnNiNC-based lean austenitic stainless steels. Mater. Charact. 2016, 119, 200-208. [CrossRef]

26. McCafferty, E. Validation of corrosion rates measured by the Tafel extrapolation method. Corros. Sci. 2005, 47, 3202. [CrossRef]

27. Annergren, I. Localized Electrochemical Impedance Spectroscopy for Studying Pitting Corrosion on Stainless Steels. J. Electrochem. Soc., 1997, 144, 1208. [CrossRef]

28. Chen, X.; Li, J.; Cheng, X.; Wang, H.; Huang, Z. Effect of heat treatment on microstructure, mechanical and corrosion properties of austenitic stainless steel $316 \mathrm{~L}$ using arc additive manufacturing. Mater. Sci. Eng. A 2018, 715, 307-314. [CrossRef]

29. Chen, C.; Lu, M.; Sun, D.; Zhang, Z.; Chang, W. Effect of Chromium on the Pitting Resistance of Oil Tube Steel in a Carbon Dioxide Corrosion System. Corrosion 2005, 61, 594-601. [CrossRef]

30. Jiang, S.; Chai, F.; Su, H.; Yang, C. Influence of chromium on the flow-accelerated corrosion behavior of low alloy steels in 3.5\% NaCl solution. Corros. Sci. 2017, 123, 217-227. [CrossRef]

31. Ziętala, M.; Durejko, T.; Polański, M.; Kunce, I.; Płociński, T.; Zieliński, W.; Łazińska, M.; Stępniowski, W.; Czujko, T.; Kurzydłowski, K.; et al. The microstructure, mechanical properties and corrosion resistance of 316L stainless steel fabricated using laser engineered net shaping. Mater. Sci. Eng. A 2016, 677, 1-10. [CrossRef]

(C) 2018 by the authors. Licensee MDPI, Basel, Switzerland. This article is an open access article distributed under the terms and conditions of the Creative Commons Attribution (CC BY) license (http://creativecommons.org/licenses/by/4.0/). 